\title{
The Psychometric Properties of Attitudes Toward Seeking Professional Psychological Help Scale-Short Form in Jordanian University Students
}

\author{
Ahmad Rayan ${ }^{1}$ \\ Zarqa University, Faculty of Nursing, Zarqa, Jordan \\ Arayan@zu.edu.jo
}

\section{Omar Baker}

King Saud University, College of Nursing, Riyadh, Kingdom of Saudi Arabia omarbaker1970@gmail.com

\section{Mirna Fawaz}

Beirut Arab University, Faculty of Health Sciences, Beirut, Lebanon mirna.fawaz@hotmail.com

\section{Abstract}

Attitudes Toward Seeking Professional Psychological Help Scale-Short Form (ATSPPH-SF) is a commonly used measure of mental health treatment attitudes, but its reliability and validity in an Arabic-speaking population have yet to be established. The purpose of this study is to examine the theoretical structure and the psychometric properties of the Arabic version of ATSPPH-SF among university students. A sample of 519 students completed the study. Confirmatory factor analysis was conducted to assess the factor structure of ATSPPH-SF. The relationship between the ATSPPH-SF and stigma toward mental illness were explored to examine the convergent validity. The results indicate that the 10-item ATSPPH-SF had a single-factor structure. Additionally, the ATSPPH-SF had shown an evidence of adequate internal consistency reliability and convergent validity. This preliminary study supports using the Arabic version of the 10-item ATSPPH-SF.

1. Corresponding author: Ahmed_rayan87@yahoo.com 
Keywords: Factor structure, Psychological help, Student, Jordan, ATSPPH-SF, Arabic scale

Mental health disorders are highly prevalent worldwide and seeking treatment is crucial to help affected individuals. Researchers found that Arab university students experience many psychological problems during their college years making them at high risk for mental disorders (e.g., Abujilban, Abuidhail, AlModallal, Hamaideh, \& Mosemli, 2014; Al Matarneh \& Altrawneh, 2014; Ismayilova, Hmoud, Alkhasawneh, Shaw, \& El-Bassel, 2013). Despite these risks, they tend to refuse seeking treatment or counseling services for mental health issues and often refrain from consulting professionals (Al-Krenawi, Graham, \& Kanduh, 2000; Hamid \& Furnham, 2013; Rayan \& Jaradat, 2016). Researchers who are interested in developing intervention programs to improve helpseeking attitudes may seek a valid measure to evaluate the effectiveness of their intervention. However, there are no evaluations of currently available measures of attitudes toward seeking professional psychological help and related psychometrics for Arabic-speaking populations.

Many studies have reported that attitudes toward seeking professional psychological help (ATSPPH) are associated with many different variables such as gender (Kakhnovets, 2011; Yousaf, Popat, \& Hunter, 2015) and age (Cook, Elhai, \& Areán, 2005; Ward, Wiltshire, Detry, \& Brown, 2013; Yousaf et al., 2015). Furthermore, barriers such as cultural norms, negative ATSPPH for psychiatric disorders, unfamiliarity with counseling process, concerns about cost and time, accessibility, and knowledge deficit regarding available services may adversely influence ATSPPH and reduce utilization of available resources (Fisher \& Farina, 1995; Leong \& Lau, 2001; Rayan \& Jaradat, 2016). However, despite investigating factors associated with seeking professional psychological help in various populations, few studies have been able to draw conclusions about these attitudes based on representative samples in Arabic-speaking populations.

Mental illness stigma and negative ATSPPH are reported in Arab populations where problems are usually addressed by the use of informal help strategies (i.e., talk to close friends or family) rather than mental health services (Rayan \& Fawaz, 2018; Rayan \& Jaradat, 2016). The ATSPPH among Arab university students have been investigated previously (Rayan \& Jaradat, 2016), but having a reliable and valid tool to measure these attitudes has yet to be established. Arab populations are notably underrepresented in ATSPPH research studies and no specific tool has been adapted to their cultures. Yoon and Jepsen (2008) revealed that Asian students, compared to American students, reported less utilization of counseling and professional psychological help services. Therefore, when cultural differences and diverse semantic meanings of the scales given to participants are considered, it becomes crucial to have a 
culturally sensitive, valid assessment tool to understand potential differences in ATSPPH between Arabic-speaking populations and other cultural groups.

The ATSPPH Scale-Short Form (ATSPPH-SF) is a commonly used measure of ATSPPH (Fisher \& Farina, 1995). It is a 10-item short scale adapted from the original 29-item ATSPPH Scale (Fischer \& Turners, 1970) to improve its psychometric properties. The ATSPPH-SF has adequate psychometric properties with a one-factor structure and Cronbach's alpha of 0.84 . It has been widely used with different racial and ethnic groups, including non-Western international students (Thomas, Caputi, \& Wilson, 2014; Li, Marbley, Bradley, \& Lan, 2016), African Americans, Asian Americans, and Latinos (Omizo, Kim, \& Abel, 2008; Townes, Chavez-Korell, \& Cunningham, 2009). It was translated into different languages and tested among Taiwanese, Japanese, Asian Australians, and South African students ( Leach, Jana-Masri, \& Priester, 2007; Samouilhan \& Seabi 2010).

Many studies investigated the psychometric properties of the ATSPPHSF. Elahi, Schweinle, and Anderson (2008) suggested a two-factor structure rather than one-factor structure for the ATSPPH-SF. Jana-Masri and Priester (2007) found that the Cronbach's alpha reliability of the ATSPPH-SF was 0.15. Leach and colleagues (2007) assessed the Arabic version of the ATSPPH-SF with 420 undergraduate Muslim students and found low reliability, $(\alpha)=0.35$. However, researchers did not modify the tool to be culturally appropriate for Arabs, though many studies have revealed inconsistent factorial structure and poor internal consistency reliabilities when investigated in Arab populations (Al-Darmaki, 2003; Duncan, 2003; Leach et al., 2007). Such inconsistent psychometric properties and poor cultural appropriateness necessitate more investigation and adaptation for the tool. The purpose of this study was to test the psychometric properties of the ATSPPH-SF among Arab university students by examining the factor structure and the reliability and validity of its Arabic version. We repeated the translation of the ATSPPH-SF into Arabic using a rigorous method and dropping out the items that are inconsistent with the factor structure of the original tool in Arab cultures. Such investigation promotes the line of validation research in Arab populations.

\section{Methods}

\section{Ethical Considerations}

The ethical approval for the study was obtained from Zarqa University in Jordan. Students were informed about the purpose of the study and they were invited to voluntarily participate while assuring them that confidentiality and anonymity will be maintained. The researchers obtained informed consent 
from students and told them to contact the researcher for any questions concerning this study.

\section{Procedure}

Eight Jordanian universities were selected randomly, four of them were private and the rest were public. Inclusion criteria were: (a) currently enrolled in the university; (b) a baccalaureate student; and (c) speaks Arabic as their primary language. A convenience sample of 519 students completed the study in the first semester of the academic year 2016-2017. Participating universities have an official online social network where thousands of undergraduate students have access to them. Utilizing the internet for data collection permits researchers to collect data and store surveys in a way fit for analysis, diminishing expenses and paperwork. Research has shown no significant difference in data quality when compared information collected online versus other methods (Birnbaum, 2004). In this study, a self-administered electronic survey was used by collaborating with web managers using Facebook; the managers within selected universities sent the consent form and survey via an online link to a convenience sample of students included on each Facebook page. Only 519 students completed the study out of 1634 students who were initially invited to participate.

Necessary precautions to overcome methodological limitations were considered in this study by allowing only one opportunity for participating students to access the online link given, and incentives were avoided to prevent several attempts by the same participant. The survey included a question asking "are you currently a university student?" Respondents who replied with "no" were not included in data analysis. Repeated records were removed by data filtering and participants were not allowed to submit any questionnaire with missing data.

\section{Instruments}

Two separate scales were completed by students: the social distance scale that measures stigma toward mental illness (Martin, Pescosolido, \& Tuch, 2000) and the ATSPPH Short Form (ATSPPH-SF) which measures ATSPPH (Fischer \& Turner, 1970). Also, demographic data were collected from all participants.

\section{Social Distance Scale}

The Social Distance Scale (Martin et al., 2000) is a 6-item questionnaire measures stigma against mental illness. It concentrates on the attitudes towards 
mentally ill patients by asking participants to rate the extent to which they are willing to interact with a person diagnosed with a mental illness. Scores on this scale range from 1 to 4 , higher scores on this measure indicate higher stigma. The scale has Cronbach's alpha values of more than 0.80 , indicating very good to excellent internal consistency reliability (Link, Yang, Phelan, \& Collins, 2004).

\section{ATSPPH-SF}

The ATSPPH-SF is a 10-item measure used to assess ATSPPH on a 4-point Likert scale, ranging from 0 to 3 . Higher total score indicates more positive ATSPPH and is associated with lower levels of stigma against mental illness (Elahi et al., 2008). The ATSPPH-SF was reported to have unidimensional structure with Cronbach's alpha values of 0.84 . Construct validity was reported to be 0.87 , which was estimated by correlating it with the longer version (Fischer \& Farina, 1995).

\section{Participants}

A total number of 519 (360 females and 159 males) students completed study measures. The mean age of the participants was $22.39(\mathrm{SD}=2.96)$, ranging from 19 to 35 years. Only 91 students (17.5\%) were married. About $96 \%$ of the students have never received any psychiatric treatment. A total of 276 students (53.2\%) were majoring in a non-medicine-related specialty and the rest were studying medical specialties: medicine, pharmacy, nursing, rehabilitation sciences, clinical psychology, and allied medical sciences. Data was collected in the first semester of the 2016-2017 academic year.

\section{Translation Procedure}

The original 10-item ATSPPH-SF was translated into Arabic and the comparability of conceptual equivalence and meaning of the items was assured. This tool was first translated into Arabic. Then, another two English language editors carried out the back-translation process from Arabic into English. After that, the translators met and confirmed the comparability of both forms in terms of conceptual meaning. One psychiatric nurse and one doctor in clinical psychology made the final review and accepted the Arabic version. Students who were involved in pilot testing reported no problem in understanding any Arabic. 


\section{Data Analysis}

The SPSS 21 program was used to analyze the data. Data screening was first performed to examine normality, missing values, and outliers or any errors in data entry. Cronbach's alpha was used to estimate the internal consistency of the Arabic version of the 10-item ATSPPH-SF. Exploratory Factor Analysis (EFA) was used to assess whether the 10-item ATSPPH-SF would provide evidence for a 1-factor solution. Confirmatory factor analysis (CFA) was subsequently conducted to confirm the factor structure of the 10-item ATSPPH-SF among university students. When CFA follows an EFA on the same data set, they complement each other (Munro 2005). The goodness of fit index (GFI) and adjusted goodness of fit index (AGFI) were estimated to assess model fit. The maximum value for each of these indices is 1 and values more than 0.90 indicate a good fit (Wang, Fan, \& Willson, 1996). Additionally, the overall model fit was assessed using the Root Mean Square Error of Approximation (RMSEA). A value of the RMSEA of about 0.05 or less would indicate a "close model fit", and values greater than 0.1 suggests rejecting the model (Browne \& Cudeck, 1989). To assess the convergent validity of the 10-item ATSPPH-SF, Pearson's product-moment correlations were conducted between the 10-item ATSPPH-SF and the social distance scale where negative correlations suggest adequate convergent validity.

\section{Results}

Preliminary data screening revealed that ATSPPH-SF and the social distance scale had approximately normally distributed shape with no evidence of extreme outliers. Table 1 presents descriptive statistics for study variables.

A Maximum Likelihood Analysis was performed with the 10 items in the original ATSPPH-SF (Table 2). All of the 10 items were initially retained on one factor (factor 1). The 10 items accounted for a cumulative variance of $29.8 \%$. The Kaiser-Meyer-Oklin (KMO) in the study model was 0.76 , which is considered acceptable. The KMO is considered acceptable when it has a value of greater than 0.50 (Kaiser, 1974). Bartlett's Test of Sphericity in this study

Table 1. Descriptive Statistics for Study Variables

\begin{tabular}{lcccccc}
\hline Measure & Min & Max & Mean & SD & Skewness & Kurtosis \\
\hline ATSPPH-SF & 1 & 29 & 15.7 & 4 & $-.113-$ & .80 \\
ATSPPH-29 & 17 & 79 & 46.9 & 9.8 & .015 & .67 \\
SDS & 6 & 74 & 13.3 & 4.1 & .401 & $-.31-$ \\
\hline
\end{tabular}

Note. ATSPPH-SF = Attitudes Toward Seeking Professional Psychological Help Scale-Short Form; ATSPPH-29 = 29-Item Attitudes Toward Seeking Professional Psychological Help Scale-Short Form; SDS $=$ Social Distance Scale. 
Table 2. Standardized Factor Loadings for the Items of the 10-item ATSPPH-SF

\begin{tabular}{|c|c|c|c|c|c|}
\hline & \multirow[b]{2}{*}{ Item (English) } & \multirow[b]{2}{*}{ Item (Arabic) } & & \multicolumn{2}{|c|}{ Factor loading } \\
\hline & & & & Factor 1 & Factor 2 \\
\hline 1. & $\begin{array}{l}\text { If I believed I was having a } \\
\text { mental breakdown, my first } \\
\text { inclination would be to get } \\
\text { professional attention. }\end{array}$ & 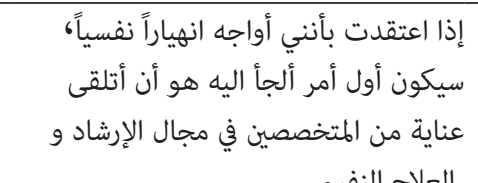 & .1 & .459 & $-.144-$ \\
\hline 2. & $\begin{array}{l}\text { The idea of talking about prob- } \\
\text { lems with a counselor strikes } \\
\text { me as a poor way to get rid of } \\
\text { emotional conflicts. }\end{array}$ & 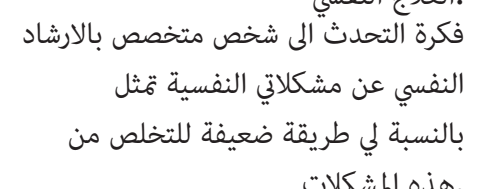 & .2 & .502 & $-.319-$ \\
\hline 3. & $\begin{array}{l}\text { If I were experiencing a serious } \\
\text { emotional crisis at this point } \\
\text { in my life, I would be confi- } \\
\text { dent that I could find relief in } \\
\text { counseling. }\end{array}$ & 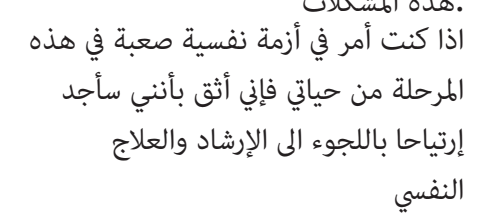 & .3 & .334 & .215 \\
\hline 4. & $\begin{array}{l}\text { There is something admirable in } \\
\text { the attitude of a person who } \\
\text { is willing to cope with his or } \\
\text { her conflicts and fears without } \\
\text { resorting to professional help. }\end{array}$ & 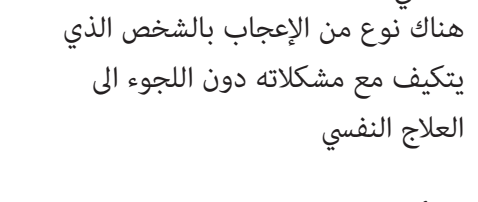 & .4 & .481 & $-.231-$ \\
\hline 5. & $\begin{array}{l}\text { I would want to get psychological } \\
\text { help if I were worried or upset } \\
\text { for a long period of time. }\end{array}$ & 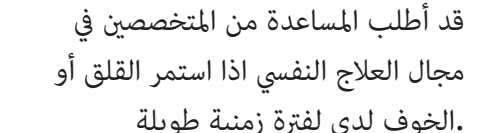 & .5 & .381 & .286 \\
\hline 6. & $\begin{array}{l}\text { I might want to have psychologi- } \\
\text { cal counseling in the future. }\end{array}$ & .قد أُحتاج للإِرشاد النفّي في المستقبل. & .6 & .402 & .212 \\
\hline 7. & $\begin{array}{l}\text { A person with an emotional } \\
\text { problem is not likely to solve } \\
\text { it alone; he or she is likely to } \\
\text { solve it with professional help. }\end{array}$ & 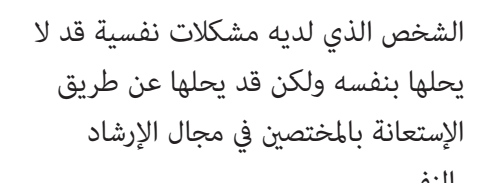 & .7 & .564 & .274 \\
\hline 8. & $\begin{array}{l}\text { Considering the time and ex- } \\
\text { pense involved in counseling, } \\
\text { it would have doubtful value } \\
\text { for a person like me. }\end{array}$ & نظفرا للوّقت والتكلفة المالية التي يتطلبها & .8 & .393 & .309 \\
\hline 9. & $\begin{array}{l}\text { A person should work out his } \\
\text { or her own problems; getting } \\
\text { psychological counseling } \\
\text { would be a last resort. }\end{array}$ & بنفب أن يقوم الشخص بحل مشاكله & .9 & .490 & $-.294-$ \\
\hline 10. & $\begin{array}{l}\text { Personal and emotional troubles, } \\
\text { like many things, tend to work } \\
\text { out by themselves. }\end{array}$ & 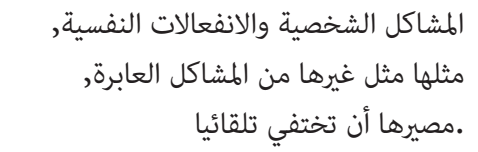 & .10 & .428 & .087 \\
\hline
\end{tabular}


was significant $(P<0.001)$, which supports that included items have a shared variance and reject the hypothesis stating that there are no common factors (Tabachnick \& Fidell, 2012). The Cronbach's alpha for the 10-item one-factor model of ATSPPH-SF in the current study was 0.72 . Univariate and multivariate normalities were examined. Analysis of Moment Structure (AMOS, version 21.0) software examined multivariate normality of the data. All items had skewness values of less than 1 and kurtosis values of less than 2 , suggesting the distributions of all of the 10 items in this study were normally distributed (Nunnally \& Bernstein, 1994).

Confirmatory factor analysis (CFA) was performed using a Maximum Likelihood Analysis method of estimation to determine whether the hypothesized model fits the actual data set. For a better model over the hypothesized model, modification indices were consulted. CFA was frequently conducted as guided by modification indices and correlations between items and items residual variances (Table 3). However, no substantial improvement in the model was observed after deleting some items as guided by the modification indices, which led to retaining all of the 10 items (Figure 1).

Table 3. Goodness-of-Fit Indices for the Two Models

\begin{tabular}{lcccccc}
\hline Model & X2 & d.f.* & $P^{*}$ & GFI $^{*}$ & AGFI* $^{*}$ & RMSEA $^{*}$ \\
\hline 10 items & 90.96 & 35 & $>0.001$ & 0.94 & 0.91 & 0.05 \\
\hline
\end{tabular}

${ }^{*} \mathrm{GFI}$, Goodness of Fit index; AGFI, Adjusted GFI; RMSEA, root mean square error of approximation.

Finally, as shown in Table 4, the 10-item ATSPPH-SF was negatively correlated with SDS and positively correlated with the 29-item longer version of the scale (Fischer \& Farina, 1995). These outcomes provide preliminary evidence regarding the convergent validity of the 10 -item of ATSPPH-SF.

Table 4. Pearson's Product-Moment Correlations Between the 8-item ATSPPH-SF and the SDS and the ATSPPH-10 and ATSPPH-29

\begin{tabular}{lccc}
\hline Variable & SDS & ATSPPH-10 & ATSPPH-29 \\
\hline The 10-item ATSPPH-SF & $-.24^{\star \star}$ & $-.96^{\star \star}$ & $-.85^{\star \star}$ \\
\hline$\star \star$ & P $<0.01$ \\
Note. ATSPPH-SF= Attitudes Toward Seeking Professional Psychological Help Scale-Short Form; \\
$\begin{array}{l}\text { SDS= Social Distance Scale; ATSPPH-10=10-Item Attitudes Toward Seeking Professional Psychologi- } \\
\text { cal Help Scale-Short Form }\end{array}$
\end{tabular}

\section{Discussion}

The 10-item model of ATSPPH-SF has good reliability and validity with Arab university students. Literature suggests that Arab cultural factors characterized by limited trust in the mental health professionals and the mental health ser- 


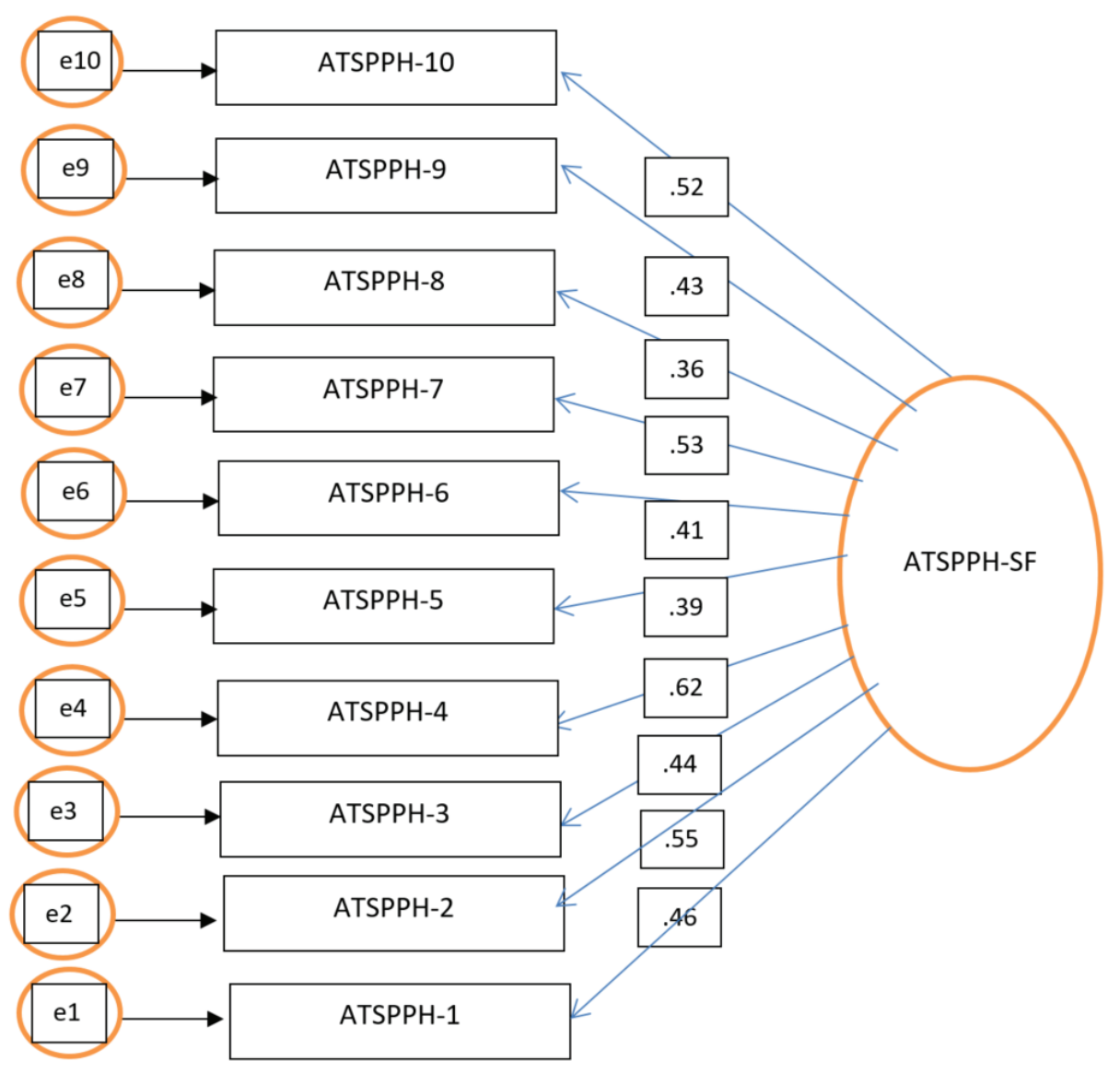

Figure 1. Standardized estimates for the 10-item ATSPPH.

vices among the Arab population might limit their utilization of mental health services (Rayan \& Fawaz, 2018; Rayan \& Jaradat, 2016). However, there was a need to find a specific tool that measures ATSPPH. Such a tool would be helpful to correlate ATSPPH with various cultural misconceptions about mental illness, and develop relevant interventions that could change these attitudes. Arab students may belief to some degree in the importance of psychological help-seeking, but most of them do not trust psychological professional help providers. They might believe that social support and confrontation or talking to friends are better than professional psychological help-seeking (Rayan \& Fawaz, 2018; Rayan \& Jaradat, 2016).

Given the goodness-of-fit of the 10-item ATSPPH-SF, this tool can be used in Arabic-speaking populations. The good reliability coefficients of the Arabic 10-item ATSPPH-SF could indicate that these 10 items had a high percent of equivalence for the concept of help-seeking compared to that in Western cultures. Subsequently, the 10-item ATSPPH-SF could be used as an accurate 
measure to assess ATSPPH in Arab populations. The original 29-item and the 10-item ATSPPH-SF were originally developed to be used to be used among American samples that trust doctors and psychiatrists. Examples of items that reflect trust in psychiatric health care professionals and professional psychiatric help services are item 2, "The idea of talking about problems with a psychologist strikes me as a poor way to get rid of emotional conflict," and item

4, "There is something admirable in the attitude of a person who is willing to cope with his conflicts and fears without resorting to professional help." However, many Arab populations usually avoid seeking psychological help services due to the lack of knowledge about counseling, limited access to psychiatric services, and lack of trust in psychiatric health care professionals. These aspects might be associated with relatively low scores on ATSPPH-SF compared with to American samples.

The current psychometric study has a limitation of using quantitative analysis only. Future studies may want to examine specific themes using qualitative data to provide in-depth information. Despite this limitation, this study provided valuable data regarding the psychometric properties of the ATSPPHShort Form to be used by health care professionals to assess ATSPPH among Arab populations.

Future research is needed to examine the test-retest reliability of the 10item ATSPPH in Arab samples. Another recommendation might include examining the differences in ATSPPH in consideration of Arab cultural values or beliefs. Moreover, extending the outcomes of the study to various age groups or Arab peoples of other countries is also recommended.

\section{Acknowledgements}

This research was funded by the Deanship of Research and Graduate Studies, Zarqa University, Jordan.

\section{References}

Abujilban, S. K., Abuidhail, J., Al-Modallal, H., Hamaideh, S., \&Mosemli, O. (2014). Predictors of antenatal depression among Jordanian pregnant women in their third trimester. Health Care for Women International, 35(2), 200-215. https://doi. org/10.1080/07399332.2013.817411

Al Matarneh, A. J., \& Altrawneh, A. (2014). Constructing a scale of future anxiety for the students at public Jordanian universities. International Journal of Academic Research, 6(5), 180-188.

Al-Darmaki, F. R. (2003). Attitudes towards seeking professional psychological help: What really counts for United Arab Emirates university students? Social Behavior and Personality, 31(5), 497-508. https://doi.org/10.2224/sbp.2003.31.5.497 
Al-Krenawi, A., \& Graham, J. R. (2000). Culturally sensitive social work practice with Arab clients in mental health settings. Health \& Social Work, 25(1), 9-22. https:// doi.org/10.1093/hsw/25.1.9

Birnbaum, M. H. (2004). Human research and data collection via the Internet. The Annual Review of Psychology, 55, 803-832. https://doi.org/10.1146/annurev. psych.55.090902.141601

Browne, M. W., \& Cudeck, R. (1989). Single sample cross-validation indices for covariance structures. Multivariate Behavioral Research, 24(4), 445-455. https://doi. org/10.1207/s15327906mbr2404_4

Duncan, L. E. (2003). Black male college students' attitudes toward seeking psychological help. Journal of Black Psychology, 29, 68-86. https://doi. org/10.1177/0095798402239229

Cook, J. M., Elhai, J. D., \& Areán, P. A. (2005). Psychometric properties of the PTSD Checklist with older primary care patients. Journal of traumatic stress, 18(4), 371376. https://doi.org/10.1002/jts.20038

Elahi, J. D., Schweinle, W., \& Anderson, S. M. (2008). Reliability and validity of the Attitudes Toward Seeking Professional Psychological Help Scale-short form. Psychiatry Research, 159, 320-329. https://doi.org/10.1016/j.psychres.2007.04.020

Fisher, E. H., \& Farina, A. (1995). Attitudes Toward Seeking Professional Psychological Help: A shortened form and considerations of research. Journal of College Student Development, 36, 368-373. https://doi.org/10.1037/t05375-000

Fischer, E. H., \& Turner, J. L. (1970). Orientations to seeking professional help: Development and research utility of an attitude scale. Journal of Consulting and Clinical Psychology, 35(1), 79-90. https://doi.org/10.1037/h0029636

Hamid, A., \& Furnham, A. (2013). Factors affecting attitude towards seeking professional help for mental illness: A UK Arab perspective. Mental Health, Religion \& Culture, 16(7), 741-758. https://doi.org/10.1080/13674676.2012.718753

Ismayilova, L., Hmoud, O., Alkhasawneh, E., Shaw, S., \& El-Bassel, N. (2013). Depressive symptoms among Jordanian youth: Results of a national survey. Community Mental Health Journal, 49(1), 133-140. https://doi.org/10.1007/s10597-012-95297

Jana-Masri, A. (2009). Attitudes Toward Seeking Professional Psychological Help Scale in Egypt: Its factor structure and relationship to Islamic beliefs and behaviors. Research in the Social Scientific Study of Religion, 20, 281-296. https://doi. org/10.1163/ej.9789004175624.i-334.98

Jana-Masri, A., \& Priester, P. E. (2007). The development and validation of a Qur'anbased instrument to assess Islamic religiosity: The Religiosity of Islam Scale. Journal of Muslim Mental Health, 2, 177-188. https://doi.org/10.1080/15564900701624436

Kakhnovets, R. (2011). Relationships among personality, expectations about counseling, and help-seeking attitudes. Journal of Counseling \& Development, 89, 11-19. https://doi.org/10.1002/j.1556-6678.2011.tb00056.x

Leach, M. M., Jana-Masri, A., \& Priester, P. E. (2007). Attitudes toward seeking professional help scale in Egypt: Its factor structure and relationship to Islamic beliefs and behaviors. Research in the Social Scientific Study of Religion, 20, 281-296. https://doi.org/10.1163/ej.9789004175624.i-334.98

Leong, F. T. L., \& Lau, A. S. (2001). Barriers to providing effective mental health services to Asian Americans. Mental Health Service Research, 3, 201-214. https://doi. org/10.1023/A:1013177014788

Li, J., Marbley, A. F., Bradley, L. J., \& Lan, W. (2016). Attitudes toward seeking profes- 
sional counseling services among Chinese international students: Acculturation, ethnic identity, and English proficiency. Journal of Multicultural Counseling and Development, 44(1), 65-76. https://doi.org/10.1002/jmcd.12037

Link, B. G., Yang, L. H., Phelan, J. C., \& Collins, P. Y. (2004). Measuring mental illness stigma. Schizophrenia Bulletin, 30(3), 511-541. https://doi.org/10.1093/oxfordjournals.schbul.a007098

Martin, J. K., Pescosolido, B. A., \& Tuch, S. A. (2000). Of fear and loathing: The role of 'disturbing behavior,' labels, and causal attributions in shaping public attitudes toward people with mental illness. Journal of Health and Social Behavior, 41 (2), 208-223. https://doi.org/10.2307/2676306

Munro, B. (2005) Statistical Methods for Health Care Research (5th ed). Philadelphia: Lippincott Williams \& Wilkins.

Nunnally, J. C., \& Bernstein, I. H. (1994). Psychological theory. New York, NY: MacGraw-Hill.

Omizo, M. M., Kim, B. S. K., \& Abel, N. R. (2008). Asian and European American cultural values, bicultural competence, and attitudes toward seeking professional psychological help among Asian American adolescents. Journal of Multicultural Counseling and Development, 36, 15-29. https://doi.org/10.1002/j.2161-1912.2008. tb00066.x

Rayan, A., \& Fawaz, M. (2018). Cultural misconceptions and public stigma against mental illness among Lebanese university students. Perspectives in Psychiatric Care, 54(2), 258-265. https://doi.org/10.1111/ppc.12232

Rayan, A., \& Jaradat, A. (2016). Stigma of mental illness and attitudes toward psychological help-seeking in Jordanian university students. Research in Psychology and Behavioral Sciences, 4(1), 7-14.

Samouilhan, T., \& Seabi, J. (2010). University students' beliefs about the causes and treatments of mental illness. South African Journal of Psychology, 40, 74-89. https:// doi.org/10.1177/008124631004000108

Tabachnick, B. G., Fidell, L. S., Tabachnick, B. G., \& Fidell, L. S. (2012). Using multivariate statistics. London: Pearson.

Thomas, S. J., Caputi, P., \& Wilson, C. J. (2014). Specific attitudes which predict psychology students' intentions to seek help for psychological distress. Journal of Clinical Psychology, 70(3), 273-282. https://doi.org/10.1002/jclp.22022

Townes, D. L., Chavez-Korell, S., \& Cunningham, N. J. (2009). Examining the relationships between racial identity, cultural mistrust, help-seeking attitudes, and preference for a black counselor. Journal of Counseling Psychology, 56, 330-336. https:// doi.org/10.1037/a0015449

Wang, L., Fan, X., \& Willson, V. L. (1996). Effects of nonnormal data on parameter estimates and fit indices for a model with latent and manifest variables: An empirical study. Structural Equation Modeling, 3(3), 228-247. https://doi. org/10.1080/10705519609540042

Ward, E., Wiltshire, J. C., Detry, M. A., \& Brown, R. L. (2013). African American men and women's attitude toward mental illness, perceptions of stigma, and preferred coping behaviors. Nursing Research, 62(3), 185-194. https://doi.org/10.1097/ NNR.0b013e31827bf533

WHO. (2011). WHO-aims report on mental health system in Jordan. Retrieved from http://www.who.int/mental_health/evidence/mh_aims_report_jordan_ jan_2011_en.pdf.

Yoon, E., \& Jepsen, D. (2008). Expectations of and attitudes toward counseling: A com- 
parison of Asian international and U.S. graduate students. International Journal for the Advancement of Counseling, 30, 116-127. https://doi.org/10.1007/s10447008-9050-4

Yousaf, O., Popat, A., \& Hunter, M. S. (2015). An investigation of masculinity attitudes, gender, and attitudes toward psychological help-seeking. Psychology of Men \& Masculinity, 16(2), 234-237. https://doi.org/10.1037/a0036241

Zawawi, J. A., \& Hamaideh, S. H. (2009). Depressive symptoms and their correlates with locus of control and satisfaction with life among Jordanian college students. Europe's Journal of Psychology, 5(4), 71-103. https://doi.org/10.5964/ejop.v5i4.241 
